\title{
Modeling the run of a control program for turning a GTE disk compressor workpiece on a CTX Alpha 500 virtual dual-spindle CNC lathe
}

\author{
Aleksandr Ryazanov ${ }^{1, *}$, and Aleksey Shvetsov ${ }^{1}$ \\ ${ }^{1}$ Samara University, 34 Moskovskoye Shosse, Samara, 443086, Russia
}

\begin{abstract}
The paper discusses a way to minimize the machine time to debug a control program. We propose performing most of the debugging on a 3D copy of a CNC metal-cutting machine. We herein present an example of how a compressor disk turning control program could be created and verified by a CTX alpha 500 virtual machine using Sinumerik 840D CNC system.
\end{abstract}

\section{Introduction}

Modern-day facilities are replacing the obsolete universal metal-cutting machines with their $\mathrm{CNC}$ counterparts. When implementing a CNC machine, one has to modernize the part production processes [1] and write new machining control programs (CP) [2]. Technologists, programmers, and $\mathrm{CNC}$ operators need retraining [3]. Operator retraining courses consist of theory lectures and practical machining exercises. A factory may not always have proper conditions for training. Unavoidable mistakes that trainees make might result in injuries, damage to expensive equipment, and jeopardization of the manufacturing process. Programmers write control programs without direct access to the machine. However, a CP cannot be deemed properly debugged until it has produced at least one usable part. Like the operator, the programmer must understand how the machinery works for which they are writing a control program.

Minimizing the machine time to debug control programs and to retrain specialists is a relevant and practically significant problem.

\section{Materials and methods}

Many modern computer-aided manufacturing systems enable the user to model the part shaping process in a virtual machine environment [4]. Paper [5] presents a lab where personal PCs are used as CNC stands. They run systems by the world's leading developers: Heidenhain, Siemens Sinumerik, HAAS. CNC controls connected to such PCs are identical to those used in the actual manufacturing process. Machining is modeled in the limited $\mathrm{CNC}$ interfaces by these developers.

\footnotetext{
*Corresponding author: tr05@bk.ru
} 
Paper [3] is about a lab of small CNC machines. It also uses PCs are CNC stands. Control programs are written in the ADEM CAD system. It can model the workpiece machining process based on a written control program. The sequential movement of the cutter or the removal of stock from the workpiece can be watched in real time or step-bystep. Small-size lathes and mills are connected to the lab PCs. They use the developed control programs to produce test parts. This approach can be used to fully write and debug a control program before it is sent to the factory. However, the lab is limited to only simple metal-cutting machines.

The authors of $[6,7]$ have developed multiple digital models of popular metal-cutting machines. They modeled S500L and Mikron UCP 600 Vario machining centers in Siemens $\mathrm{NX}$, as well as a VZ-630F4 grinding machine in Vericut [8]. Such virtual models are exact kinematic copes of the original machines and can therefore simulate how actuating elements move, collide, or leave the operation area while running a CP. However, creating a control program in Siemens NX or Vericult interface is not the same as using an industrial $\mathrm{CNC}$ stand.

The authors hereof use an approach that combines the advantages of the above approaches while having none of their disadvantages. DMG Virtual Machine is a software suit designed for the virtual simulation of the part shaping process [9]. One can load a 3D machine model into its environment and use it to move the actuators, the 3D cutter model, and the tooling. DMG Virtual Machine is compatible with CNC systems by various developers. The system can be installed on a PC to create control programs to be further sent to a virtual machine. The machine is controlled via the CNC interface as if it was an actual machine used in production.

Let us analyze the approach by presenting the example of a CTX alpha 500 lathe using Sinumerik 840D CNC. Write a control program for turning a gas-turbine engine (GTE) compressor disk and debug it by simulating the part shaping process.

\section{Compressor disk machining route and developing a control program in SInumerik 840D}

CTX alpha 500 is a machine designed for turning, boring, drilling, threading, and other turning operations. It contains two integrated fast-acceleration/deceleration stepless spindle drives. Counter-spindles enable all-round workpiece machining in a single pass. The tailstock moves along the longitudinal axis to intercept the workpiece. The turret can bear power-driven tools for milling.

Siemens CNC stands are designed for factory operations and provide an interface for writing control programs directly at the machine. Beside conventional G-coding per ISO 6983-1:2009 (DIN 66025), Sinumerik 840D enables complex machining programming in ShopTurn, a special programming language. We use a virtual Sinumerik $840 \mathrm{D}$ CNC system installed on a PC.

GTE compressor disks are made from workpieces cut from a rod and containing a predrilled central hole. The workpiece is mounted by the outside diameter in the three-jaw chuck of the main spindle. The zero points of the part and the program are located where the plane of the right butt of the part intersects its rotation axis, see Fig. 1.

Fill in the cutter details in the CNC interface, such as cutter types, insert orientation and geometry, etc. Specify workpiece details, the tool withdrawal plane, and the tool replacement point. For the first operation, perform central-hole fine boring. In Sinumerik $840 \mathrm{D}$, choose a cutter, specify the machining parameters and the limits of stock removal. 


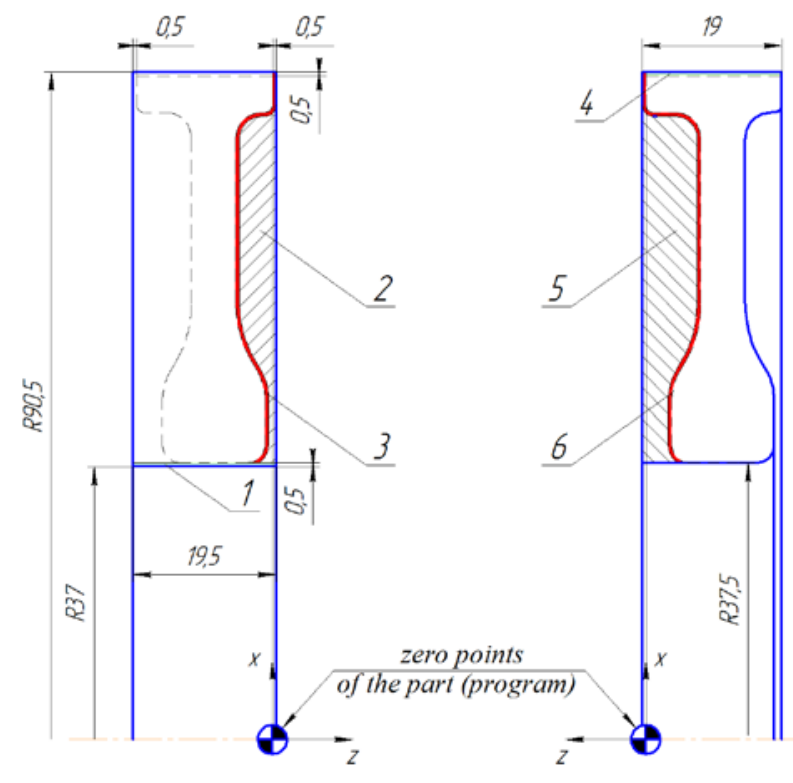

Fig. 1. Stock removal sequence: 1 Central-hole stock,

2 and 5 Roughing stock removal, 3 and 6 Finishing stock removal, 4 Inner-surface stock

Further specify the contour that positions the right surfaces to be turned. Machining by contour consists of two stages: first, we do rough machining with some removable stock left; then we finish it. Fig. 2 shows the roughing setting interface. In this interface, the operator specifies the cutting speed, the tool feed rate, the stock to be removed by finishing, the tool movement area when operating at the regular feed rate, the penetration feed rate, etc. Finishing uses the same contour as roughing. Choose the cutting parameters and the machining direction in the appropriate $\mathrm{CNC}$ window.

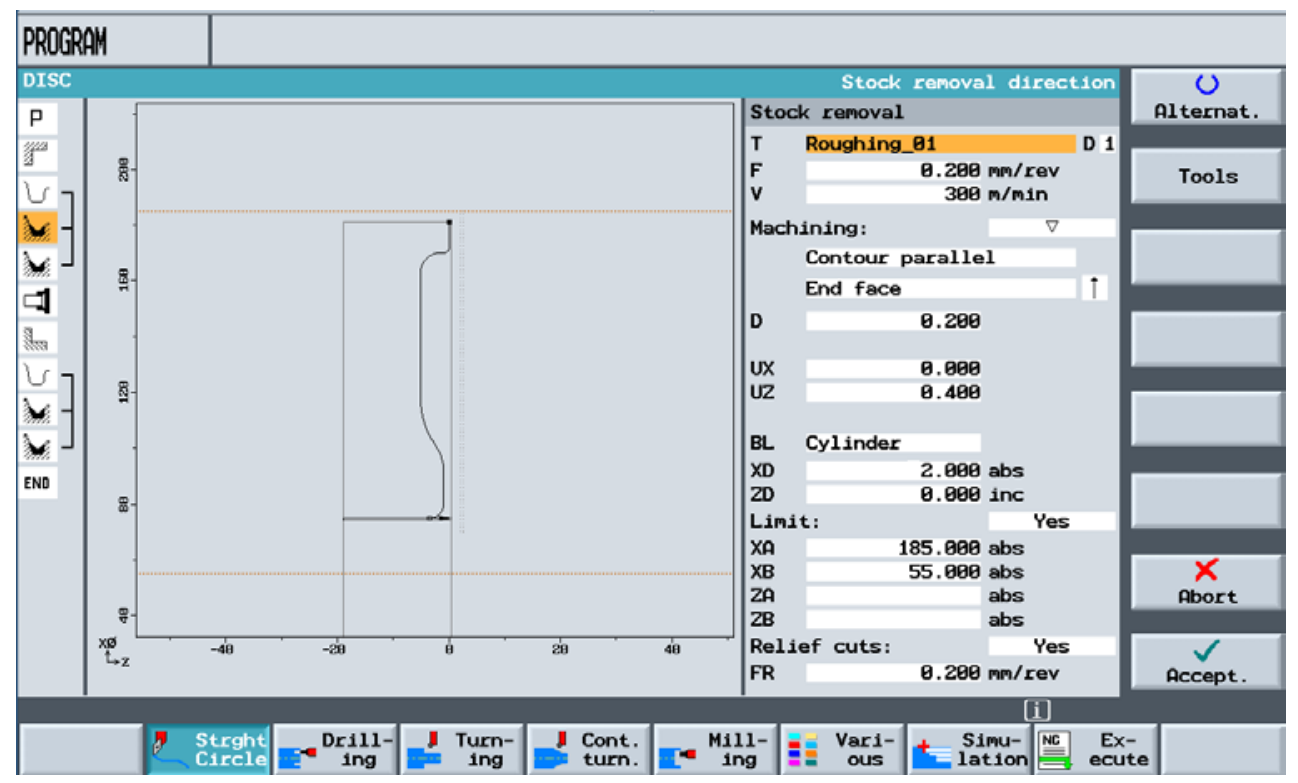

Fig. 2. Right-contour roughing parameters 
When the right side of the part is fully shaped, program the automatic capture of the workpiece by its minimum unclamping diameter; the workpiece is captured by the threejaw chuck of the counter-spindle. The zero points of the part and the program are located where the plane of the right butt of the part intersects its rotation axis. The longitudinal axis $\mathrm{Z}$ has its direction reversed, see Fig. 1.

Further specify the inner surface turning operation in Sinumerik $840 \mathrm{D}$, the command it to machine the entire left-side surface of the compressor disk. These operations are programmed in the same way as the right-side operations.

\section{Simulating the workpiece machining process by means of DMG Virtual Machine}

Load a virtual CTX Alpha 500 lathe model into the DMG Virtual Machine interface, see Fig. 3. Configure the machine to turn the compressor disk workpiece. First load roughing and finishing cutters into the tool storage. Load the frontal and the rear 3-jaw chucks. Mount the disk workpiece into the frontal chuck. After the machine is configured, link the Virtual Machine to the Sinumerik 840D CNC system. CTX Alpha 500 is further CNCcontrolled.

The created control program is used for shaping the GTE compressor disk. DMG Virtual Machine shows the turning process in real time. The machine's actuators move extremely realistically. The virtual machine detects their possible collisions. The removed stock is deducted from the workpiece volume, see Fig. 3. Operation by operation, the workpiece geometry is getting closer to its final form.
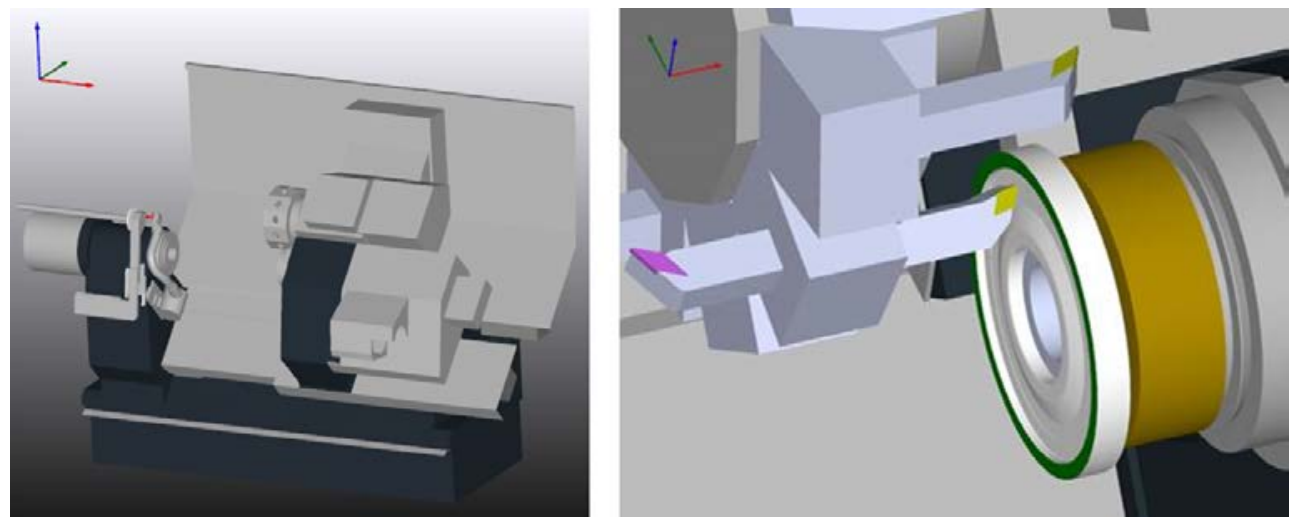

Fig. 3. CTX alpha 500, a virtual CNC lathe; left-side turning of the workpiece mounted in the counter-spindle

In parallel with virtual turning, DMG Virtual Machine simulates the run of the control program in the Sinumerik $840 \mathrm{D}$ CNC stand interface. The operator is shown how the workpiece is turned into a part, and how the cutting inserts are moved. Simulation can be three- or two-dimensional. In the latter case, one can track the tool movement trajectories. When the control program is finished, we obtain the $3 \mathrm{D}$ model of a machined disk workpiece.

\section{Conclusion}

Computer simulation of the GTE compressor disk shaping process enables partial (virtual) debugging of the control program consisting of the following stages: 
When writing a control program in ShopTurn, it is checked for the correctness of the operator's input. The CNC system asks user-friendly questions and shows animated tips. This minimizes the likelihood of errors.

When debugging the program by means of DMG Virtual Machine, the system detects possible collisions of tools, tooling, and actuators. In cases of such collisions, the CP is terminated and corrected afterwards. This prevents actual collisions that might result in injuries and damage to the equipment.

We saved the 3D model of the workpiece to a file and afterwards opened it in SolidWorks. We thus evaluated the quality of its geometry by imposing its volume onto a reference 3D model. SolidWorks interface was used to check the most important dimensions. As a result, we confirmed that the disk contour point coordinates had been calculated correctly, while the cutter approaches and withdrawals had all been performed appropriately.

Such meticulous multi-step virtual debugging is much less time-consuming than debugging by the actual metal-cutting machinery $[9,10]$. This is a more efficient of use of the machine time that makes the expensive modern CNC machines pay off faster.

A similar effect is achieved by training $\mathrm{CNC}$ programmers and operators [5]. It enables carrying out the bulk of the training in a PC lab. When coming to the factory, trainees already have basic equipment skills, make less mistakes, and learn the practicalities much faster.

\section{References}

1. D.A. Lastochkin, D.L. Skuratov, V.N. Trusov, Process Optimization in Mechanical Engineering (Optimizatsiya tekhnologicheskikh protsessov v mashinostroyenii), Textbook, Samara: STAU, p. 87 (2006)

2. A.I. Ryazanov, D.L. Skuratov, I.A. Чигринев, Simulation, process design, and manufacturing of solids-of-revolution by means of small-size CNC lathes (Tekhnologii modelirovaniya, proyektirovaniya tekhprotsessov i izgotovleniya detaley tipa tel vrashcheniya na malorazmernykh tokarnykh stankakh s ChPU), Textbook, Samara: SSAU, p. 104 (2013)

3. A.I. Ryazanov, D.L. Skuratov, L.V. Solovatskaya, Organization of classes for the simulation, process design, and manufacturing of parts in ADEM CAD/CAM/CAPP using small OPTIMUM BF20 VARIO CNC mills (Organizatsiya uchebnykh zanyaty po modelirovaniyu, proyektirovaniyu tekhprotsessov i izgotovleniyu detaley $\mathrm{v}$ $\mathrm{CAD} / \mathrm{CAM}$ /CAPP-sisteme ADEM $\mathrm{s}$ ispolzovaniyem malogabaritnykh frezernykh stankov OPTIMUM BF20 VARIO s ChPU), Engineering High-Tech (Vysokiye tekhnologii v mashinostroyenii), Samara: SamSTU, pp. 149-152 (2013)

4. A.V. Balyakin, A.I. Khaimovich, L.A. Chempinsky, Simulating high-speed milling of BT-9 titanium alloy (Modelirovaniye rezhima vysokoskorostnogo frezerovaniya titanovogo splava VT-9), Bulletin of the RAS Samara Science Center, v. 6(3), pp. 572583 (2013)

5. A.V. Balyakin, V.G. Smelov, L.A. Chempinsky, Specialist training by use of CAD/CAM systems and interactive training labs (Specialist training by use of $\mathrm{CAD} / \mathrm{CAM}$ systems and interactive training labs), Russian Aircraft Industry. Problems and Prospects (Samoletostroyeniye Rossii. Problemy i perspektivy): Proceedings of the International Symposium, Samara: SSAU, pp. 56-57 (2012)

6. A.I. Nigurey, I.V. Makarov, A.N. Zhidyayev, Specifics of building virtual kinematic models of five-axial machines (Osobennosti sozdaniya virtualnykh kinematicheskikh 
modeley pyatikoordinatnykh stankov), Bulletin of the RAS Samara Science Center, v. 19(1), pp. 269-273 (2017)

7. I.V. Makarov, A.N. Zhidyayev, A.I. Nigurey, Use of virtual machines for machining simulation (Primeneniye virtualnykh stankov dlya modelirovaniya protsessov mekhanicheskoy obrabotki), International Scientific and Technical Conference on the Problems and Prospects of Engine Construction (Problemy i perspektivy razvitiya dvigatelestroyeniya), Samara: Samara University, v. 2 pp. 209-210 (2016)

8. D.L. Skuratov, A.N. Zhidyaev, M.B. Sazonov, Solid carbide end mills tool life increase in titanium alloys machining by design development and rational choice of geometrical parameters, Research Journal of Applied Sciences, v. 9(11), pp. 767-770 (2014)

9. A.I. Ryazanov, A.N. Shvetsov, Virtual debugging of a control program for a numerically controlled five-coordinate milling machine, Russian Engineering Research, v. 36(8), pp. 677-680 (2016)

10. A.V. Balyakin, V.G. Smelov, R.A. Vdovin, Ye.M. Dobryshkina, Cost-effectiveness analysis of using computer technology in pre-production (Analiz ekonomicheskoy effektivnosti ispolzovaniya kompyuternykh tekhnology pri tekhnologicheskoy podgotovke proizvodstva), International Scientific and Technical Conference on the Problems and Prospects of Engine Construction (Problemy i perspektivy razvitiya dvigatelestroyeniya), Samara: Samara University, v. 2 pp. 203-204 (2016) 